\title{
BMJ Cardiovascular mortality in bipolar Open disorder: a population-based cohort study in Sweden
}

\author{
Jeanette Westman, ${ }^{1}$ Jonas Hällgren, ${ }^{2}$ Kristian Wahlbeck, ${ }^{3}$ David Erlinge, ${ }^{4}$ \\ Lars Alfredsson, ${ }^{5}$ Urban Ösby ${ }^{1,6,7,8}$
}

To cite: Westman J, Hällgren J, Wahlbeck K, et al. Cardiovascular mortality in bipolar disorder: a population-based cohort study in Sweden. BMJ Open 2013;3:e002373.

doi:10.1136/bmjopen-2012002373

- Prepublication history for this paper are available online. To view these files please visit the journal online (http://dx.doi.org/10.1136/ bmjopen-2012-002373).

Received 19 November 2012 Revised 22 February 2013 Accepted 25 February 2013

This final article is available for use under the terms of the Creative Commons Attribution Non-Commercial 2.0 Licence; see http://bmjopen.bmj.com

For numbered affiliations see end of article.

Correspondence to Dr Jeanette Westman; jeanette.westman@ki.se

\section{ABSTRACT}

Objective: To estimate the cardiovascular mortality among persons with bipolar disorder in Sweden compared to the general population.

Design: Population register-based cohort study with a 20-year follow-up.

Setting: Sweden.

Participants: The entire population of Sweden $(\mathrm{n}=10.6$ million) of whom 17101 persons were diagnosed with bipolar disorder between 1987 and 2006.

Main outcome measures: Mortality rate ratios (MRR), excess mortality (excess deaths), cardiovascular disorder (CVD) and specifically cerebrovascular disease, coronary heart disease, acute myocardial infarction, sudden cardiac deaths and hospital admission rate ratio (ARR).

Results: Persons with bipolar disorder died of CVD approximately 10 years earlier than the general population. One third $(38 \%)$ of all deaths in persons with bipolar disorder were caused by CVD and almost half $(44 \%)$ by other somatic diseases, whereas suicide and other external causes accounted for less than a fifth of all deaths $(18 \%)$. Excess mortality of both CVD $(n=824)$ and other somatic diseases $(n=988)$ was higher than that of suicide and other external causes ( $n=675$ deaths). MRRs for cerebrovascular disease, coronary heart disease and acute myocardial infarction were twice as high in persons with bipolar disorder compared to the general population. Despite the increased mortality of CVD, hospital admissions (ARR) for CVD treatment were only slightly increased in persons with bipolar disorder when compared to the general population.

Conclusions: The increased cardiovascular mortality in persons with bipolar disorder calls for renewed efforts to prevent and treat somatic diseases in this group. Specifically, our findings further imply that it would be critical to ensure that persons with bipolar disorder receive the same quality care for CVD as persons without bipolar disorder.

\section{INTRODUCTION}

Cardiovascular disease (CVD) is the main cause of death in many developed countries. ${ }^{1}$ CVD

\section{ARTICLE SUMMARY}

Article focus

- To estimate the mortality in cardiovascular disease (CVD) and its subgroups cerebrovascular and coronary heart disease and acute myocardial infarction among 17101 persons diagnosed with bipolar disorder in Sweden, compared to the general population in a national register study with a 20-year follow-up.

\section{Key messages}

- Persons with bipolar disorder died of CVD approximately 10 years early. Excess mortality of both CVD $(n=824)$ and other somatic diseases $(n=988)$ was higher than that of suicide and other external causes ( $n=675$ deaths). Mortality rate ratios for cerebrovascular disease, coronary heart disease and acute myocardial infarction, were twice as high compared to the general population. Despite, the increased mortality, hospital admissions, admission rate ratios for CVD treatment in persons with bipolar disorder were only slightly increased.

- The increased cardiovascular mortality in persons with bipolar disorder calls for renewed efforts to prevent and treat somatic diseases. Specifically, our findings imply that it would be critical to ensure that persons with bipolar disorder receive the same quality care for CVD as the population.

Strengths and limitations of this study

- A large national cohort with comprehensive data on patient characteristics was studied. Mortality data from the Swedish cause of death register are of high quality.

- Clinical information on symptoms and treatment was lacking.

encompasses a broad range of different conditions that are potentially life threatening. In Sweden, although mortality from CVD in the population has almost halved in the last two decades, CVD still accounts for more than $40 \%$ of all deaths in the country. ${ }^{2}$ Premature death in patients with severe mental health disorders, especially patients with schizophrenia and 
bipolar disorder, has historically been attributed to suicide. However, more recent studies have shown that CVD leads to more reduced life spans than does suicide in those patients. ${ }^{3}$ Persons with bipolar disorder have an increased risk of CVD and have been observed to die because of CVD twice as often as the general population. ${ }^{4-6}$ Although previous studies have shown an association between bipolar disorder and mortality from CVD, few studies have addressed different types of vascular mortality or examined the related use of healthcare. An improved understanding of the causes behind and magnitude of CVD among patients with bipolar disorder is warranted along with an in-depth evaluation of different diagnostic CVD subgroups. The answers to these questions, which are far less investigated in bipolar disorder than in schizophrenia, are essential in the efforts to address the problem of premature deaths owing to CVD in persons with bipolar disorder. These questions are the focus of the present national register-based study, which extends earlier Swedish findings ${ }^{5}$ both by more specific CVD mortality analyses and more recent patient data.

The aim of this study was to evaluate the excess mortality from CVD, such as cerebrovascular disease and coronary heart disease with acute myocardial infarction as its most important component, and also CVD hospital admissions in persons with bipolar disorder in Sweden between 1987 and 2006 compared to the population.

\section{METHODS}

\section{Cohort and follow-up}

All persons who resided in Sweden between the 1 January 1987 and the 31 December $2006(n=10631$ 208) were identified using the Swedish Total Population Register (TPR). The TPR was established in 1968 and contains information on sex, date and place of birth and date of migration of every resident in Sweden. Information on hospital admission, medical diagnosis and cause of death was obtained by linking the TRP with the national Swedish Cause-of-Death Register and the National Patient Register (NPR) using each resident's unique personal identification number.

The NPR, which is maintained by the National Board of Health and Welfare, contains information on all hospital in-patient treatments in Sweden since 1987. For psychiatric in-patient care, the register has nationwide coverage dating back from 1973. For each hospitalisation, the unique national registration number, date of admission and discharge and diagnosis are registered in NPR. In Sweden, all hospital diagnoses are classified according to the WHO International Classification of Diseases (ICD). Since the diagnostic definitions of affective disorders were substantially changed in ICD-9 and ICD-10 as compared with ICD-8, only patients diagnosed with bipolar disorder according to ICD-9 or ICD-10 were included in the study. Bipolar diagnoses recorded between 1987 and 1996 were identified using ICD-9 (296A, C, E and 298B). From 1997 and later, ICD-10 (F30-F31) was used to identify bipolar diagnoses.
The Swedish Cause of Death Register (CDR) includes all individuals who were registered in Sweden at the time of death. The register provides information on the date of death as well as main (underlying) and secondary causes of death based on death certificates. Definitions regarding the causes of death and ICD codes used in this study are shown in figure 1.

A total of 20248 patients admitted to hospital between 1 January 1987 and 31 December 2006 with a main diagnosis of bipolar disorder (ICD-9, ICD-10) were identified in the NPR. Of the 20248 patients, 3147 had been previously diagnosed with schizophrenia (ICD-8: 295; ICD-9: 295; ICD-10; F20, F25) and were consequently excluded. Thus, the total risk population of the study comprised of 17101 patients with bipolar disorder. The follow-up period was 20 years (1987-2006). Immigrants were included from the date of immigration to Sweden. Each person was followed until 31 December, 2006, or the date of death or emigration, depending on which came first. Inclusion in the risk population started from the date of first hospital admission (discharge diagnosis) during the study period.

\section{Statistical analysis}

Person-years at risk, number of cause-specific deaths and hospital admissions owing to CVD for both patients with bipolar disorder and the general population were determined. Person-time was stratified by sex, calendar year and age. Mortality rate ratios (MRR) and admission rate ratios (ARR) and predicted death rates were calculated with corresponding 95\% confidence intervals (CI) using Poisson regression models with the GENMOD procedure using statistical software SAS (V.9.2). All models were adjusted for or stratified by sex, attained age and year of follow-up.

To calculate the excess mortality for patients with bipolar disorder, the observed number of deaths was compared with the expected number of deaths among patients with bipolar disorder. The expected number of deaths was calculated by applying age-specific, sexspecific and calendar-specific death rates in the general population to the time at risk among the patients.

The risk of dying from CVD after first hospital admission was analysed by estimating cause-specific survival curves using the Kaplan-Meier method. Additional adjusted HRs with 95\% CIs were estimated using Cox proportional hazard models.

When hospital admission owing to CVD (admission rate ratios, ARR) was the event of interest, follow-up ended on the day of first admission. To ensure that the observed cases were incident, a 3-year run-in period was created to compensate for the lack of CVD coverage in the NPR before 1987. Hence, all patients with bipolar disorder analysed had no hospital admissions owing to CVD recorded for at least 3 years before follow-up. 
Figure 1 International

Classification of Diseases coding and classification of disease and mortality.

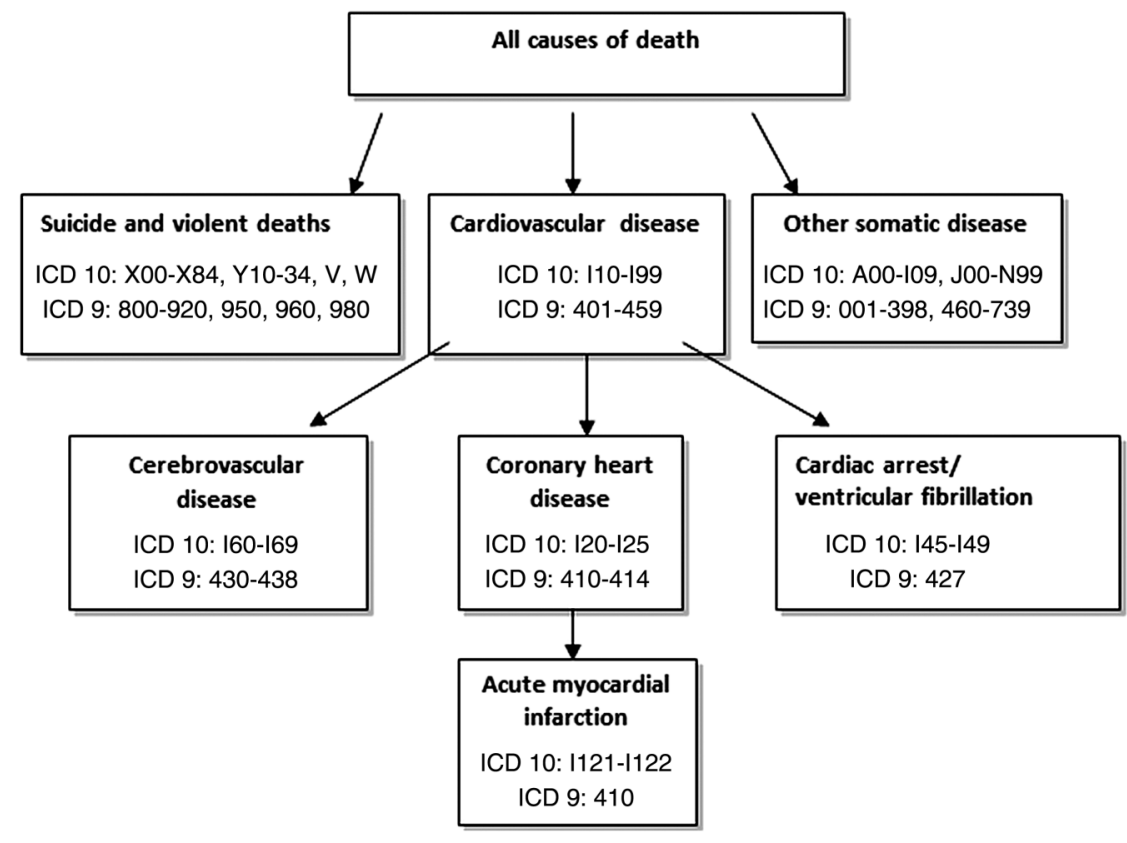

\section{RESULTS}

\section{Causes of death}

Total mortality (death from any cause) between 1987 and 2006 in Sweden was more than twice as high among patients with bipolar disorder compared to the general population (MRR 2.40; 95\% CI 2.33 to 2.47). Specifically, 2489 excess deaths in patients with bipolar disorder were observed (table 1). With mortality causes subdivided into CVD and other somatic and external causes of death, we found that men and women with bipolar disorder were twice as likely to die of CVD compared to the general population (MRR 2.03; 95\% CI 1.93 to 2.13), with 824 excess deaths owing to CVD. Mortality from other somatic causes was also doubled
(MRR 2.10; 95\% CI 2.00 to 2.19), with 988 excess deaths. External causes of death, such as suicide, homicides and accidents, were increased more than nine times in patients with bipolar disorder (MRR 9.66; 95\% CI 8.99 to 10.37), with 675 excess deaths. As far as CVD subgroups were concerned, mortality from cerebrovascular disease and coronary heart disease was twice as high in patients with bipolar disorder, with 184 excess deaths (MRR 2.00; 95\% CI 1.81 to 2.22) and 377 excess deaths (MRR 1.95; 95\% CI 1.81 to 2.09). Mortality from acute myocardial infarction was almost twice as high in patients with bipolar disorder (MRR 1.83; 95\% CI 1.67 to 2.01), with 200 excess deaths. Mortality from sudden cardiac death, cardiac arrest/ventricular fibrillation, was

Table 1 Mortality rate ratios (MRRs) for persons with bipolar disorder during 1987-2006

\begin{tabular}{|c|c|c|c|c|c|c|c|}
\hline \multirow[b]{2}{*}{ Cause of death } & \multicolumn{2}{|l|}{ Men } & \multicolumn{2}{|c|}{ Women } & \multicolumn{2}{|c|}{ Total (both sexes) } & \multirow{2}{*}{$\begin{array}{l}\text { Excess cases } \\
(95 \% \mathrm{Cl})\end{array}$} \\
\hline & Cases & MRR $(95 \% \mathrm{Cl})$ & Cases & MRR (95\% Cl) & Cases & MRR (95\% Cl) & \\
\hline $\begin{array}{l}\text { All causes of } \\
\text { death }\end{array}$ & 1874 & 2.48 (2.37 to 2.59 ) & 2393 & 2.34 (2.25 to 2.44$)$ & 4267 & 2.40 (2.33 to 2.47 ) & 2489 (2361 to 2617$)$ \\
\hline $\begin{array}{l}\text { Cardiovascular } \\
\text { disease }\end{array}$ & 733 & 2.16 (2.01 to 2.33 ) & 892 & 1.93 (1.81 to 2.06$)$ & 1625 & 2.03 (1.93 to 2.13 ) & 824 (745 to 903$)$ \\
\hline $\begin{array}{l}\text { Other somatic } \\
\text { deaths }\end{array}$ & 735 & 1.97 (1.83 to 2.11$)$ & 1154 & 2.19 (2.06 to 2.32 ) & 1889 & 2.10 (2.00 to 2.19$)$ & 988 (902 to 1073) \\
\hline $\begin{array}{l}\text { Suicide and other } \\
\text { external deaths }\end{array}$ & 406 & 9.37 (8.50 to 10.33$)$ & 347 & $10.02(9.01$ to 11.13$)$ & 753 & 9.66 (8.99 to 10.37$)$ & 675 (621 to 729$)$ \\
\hline $\begin{array}{l}\text { Cerebrovascular } \\
\text { disease }\end{array}$ & 144 & 2.29 (1.94 to 2.70$)$ & 224 & 1.86 (1.63 to 2.12$)$ & 368 & 2.00 (1.81 to 2.22$)$ & 184 (147 to 222$)$ \\
\hline $\begin{array}{l}\text { Coronary heart } \\
\text { disease }\end{array}$ & 385 & 2.00 (1.81 to 2.21$)$ & 391 & 1.89 (1.71 to 2.09$)$ & 776 & 1.95 (1.81 to 2.09$)$ & 377 (323 to 432 ) \\
\hline $\begin{array}{l}\text { Acute myocardial } \\
\text { infarction }\end{array}$ & 227 & 1.89 (1.66 to 2.15$)$ & 213 & 1.78 (1.55 to 2.03 ) & 440 & 1.83 (1.67 to 2.01$)$ & 200 (159 to 241$)$ \\
\hline $\begin{array}{l}\text { Cardiac arrest/ } \\
\text { ventricular } \\
\text { fibrillation }\end{array}$ & 23 & 2.29 (1.52 to 3.45$)$ & 32 & 1.62 (1.15 to 2.30$)$ & 55 & 1.85 (1.42 to 2.41$)$ & 25 (12 to 42 ) \\
\hline
\end{tabular}


also increased (MRR 1.85; 95\% CI 1.42 to 2.41), with 25 excess deaths. Women and men with bipolar disorder of all ages had an equally increased mortality from CVD (data not shown).

\section{Age and cause of death}

MRR by age at death for all causes of death is shown in figure 2A and subdivided into cardiovascular death (figure 2B), other somatic death (figure 2C), suicide and other external causes of death (figure 2D). Cerebrovascular death (figure 2E), death by coronary heart disease (figure 2F) and death from acute myocardial infarction (figure 2G) are reported separately.

MRR for CVD was increased for patients with bipolar disorder across all ages, but was particularly pronounced in the young age groups (figure 2B). Patients with bipolar disorder who died of CVD were younger than people in the general population. The same finding was observed when we subdivided CVD into cerebrovascular disease, coronary heart disease and acute myocardial infarction (figure $2 \mathrm{E}-\mathrm{G}$ ). For acute myocardial infarction and coronary heart disease, the increased risk was most apparent in the 55-year to 65-year age groups (figure $2 \mathrm{~F}, \mathrm{G}$ ). In the ages below 50 years, the results should be interpreted with caution because there were very few events in these ages. Death by suicide and other external causes of death were 15 times more common among patients with bipolar disorder below 30 years of age compared to persons of the same age in the general population (figure 2D). Overall, the MRR for suicide and other external causes of death decreased with increasing age. However, it should be noted that it remained significantly increased in persons aged between 70 and 74 years (MRR 6.88; CI 95\% 5.06 to 9.35; figure 2D).

Age differences at death between persons with bipolar disorder and the population from coronary heart disease, acute myocardial infarction and cerebrovascular disease are shown in figure 3A-C. The earlier age at death for persons with bipolar disorder is clearly shown for all these causes of death.

\section{Admission rates}

Hospital admission rates for CVD among patients with bipolar disorder were similar to those for the general population even though MRR for CVD was almost twice as high, independent of the specific CVD cause (tables 1 and 2). Survival rates 5 years after first hospital admission for CVD were significantly lower among patients with bipolar disorder than among the general population (figure 4).

\section{DISCUSSION}

\section{Key findings}

In this nationwide study of mortality among persons with bipolar disorder in Sweden compared to the population, somatic illness was the main cause of death. Patients with bipolar disorder died of CVD around 10 years earlier than the general population. Mortality from cerebrovascular disease, coronary heart disease and acute myocardial infarction was twice as high in patients with bipolar disorder as in the general population, while the frequency of hospital admissions owing to these diseases was not increased. Our findings showed that CVD in persons with bipolar disorder accounted for 824 excess deaths and other somatic diseases for 988 excess deaths, taken together 1812 excess deaths, both larger than suicide and other external causes of death $(n=675)$. Interestingly, sudden cardiac death was also increased.

\section{Strengths and limitations}

The Swedish National Patient Register and Cause of Death Register include everyone who resides in the country and are considered unique, comprehensive and highly credible. Currently more than $99 \%$ of all somatic and psychiatric hospital discharges are recorded in the National Patient Register. ${ }^{7}$ Swedish hospitals and government agencies are obliged by law to enter medical information in the National Patient Register. All diagnoses in the National Patient and Cause of Death registers were given by patients' doctors using international classification standards (ICD codes). Being register based, this study used information about clinical diagnoses from hospital admissions in Sweden. During the study period, the ICD diagnostic definitions were specific for bipolar disorder. A validation of the Swedish clinical bipolar hospital diagnoses has shown high validity, sufficient for epidemiological studies. ${ }^{8}$ One limitation of this study was that it was based on in-patient diagnoses, which may have generated a selective bias towards severely ill patients. However, most individuals at severe stages of bipolar disorder are admitted to hospital in Sweden. Since medical care is free in Sweden, there is no bias by costs for hospital care leading to differences in health-seeking behaviour. In a previous study, we have shown that the number and frequency of hospital admissions owing to bipolar disorder remained relatively unchanged during recent years, while the overall number of psychiatric admissions was drastically reduced. ${ }^{9}$ We did not have access to medical records or information on medical treatment. In terms of the validity of the data on causes of death, in CVD deaths, we found a slightly higher autopsy rate $(28 \%)$ among patients with bipolar disorder than in the general population $(22 \%)$. It is unlikely that these small differences affected the outcome of the study. An advantage with the present study is the analysis of specific causes of death.

\section{Findings from other studies}

The findings of this study add to the growing body of evidence that somatic diseases, particularly CVD, contribute to theshorter lifespan among patients with bipolar disorder. Findings from several large register-based studies from different parts of the world indicate that cardiovascular disease is responsible for the majority of excess deaths, with up to 2.5-fold increased mortality. ${ }^{3} 56^{6}{ }^{10-14}$ Studies using registers from the Nordic countries have shown that 
Figure 2 Mortality rate ratios (MRR) by age at death in persons with bipolar disorder compared to the general population for $(A)$ all causes of death, (B) cardiovascular death, $(C)$ other somatic death, (D) suicide and other external causes of death, (E) cerebrovascular disease, (F) coronary heart disease, and $(G)$ acute myocardial infarction. All causes of death presented with the same scale for reasons of comparison.
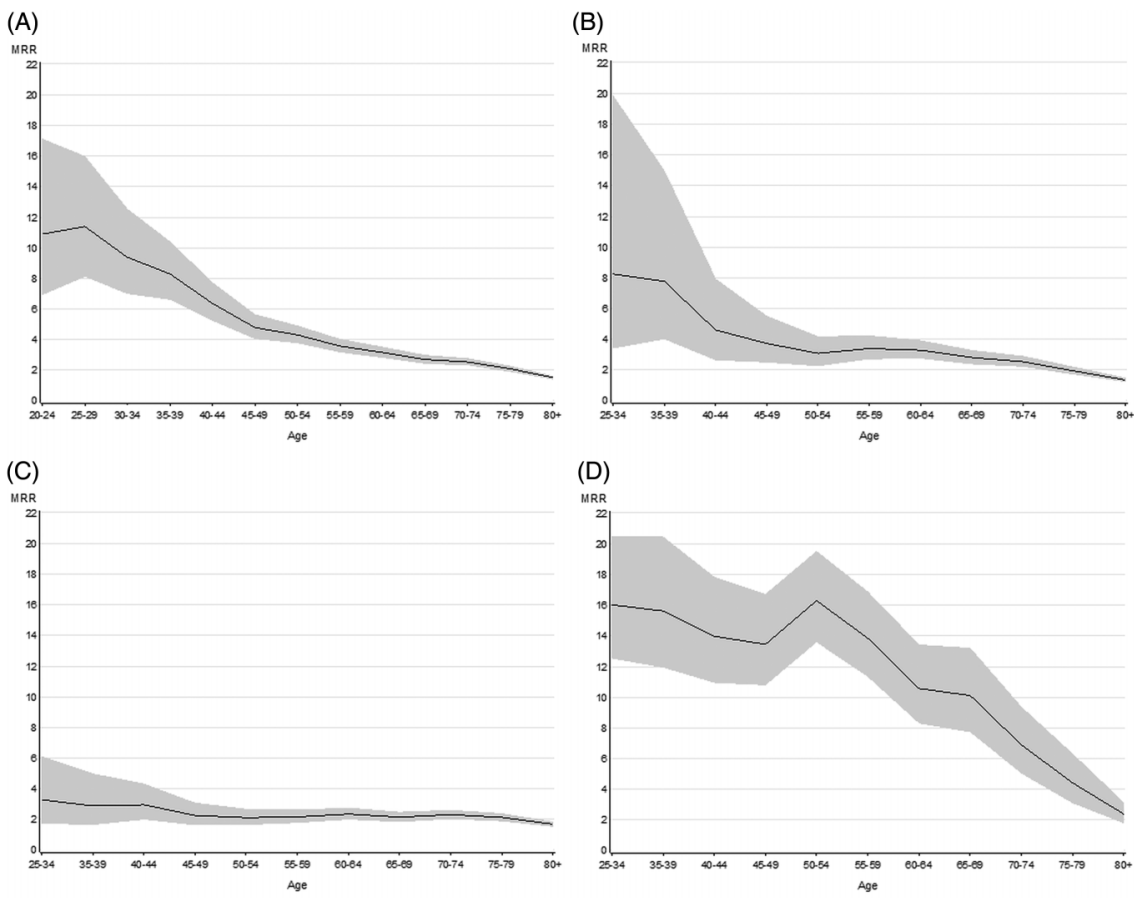

(E)

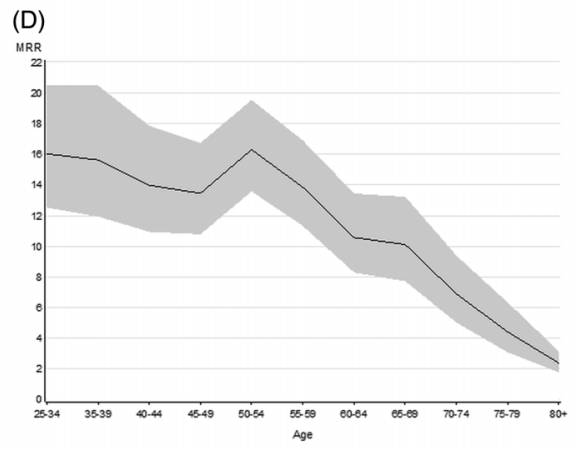

(F)
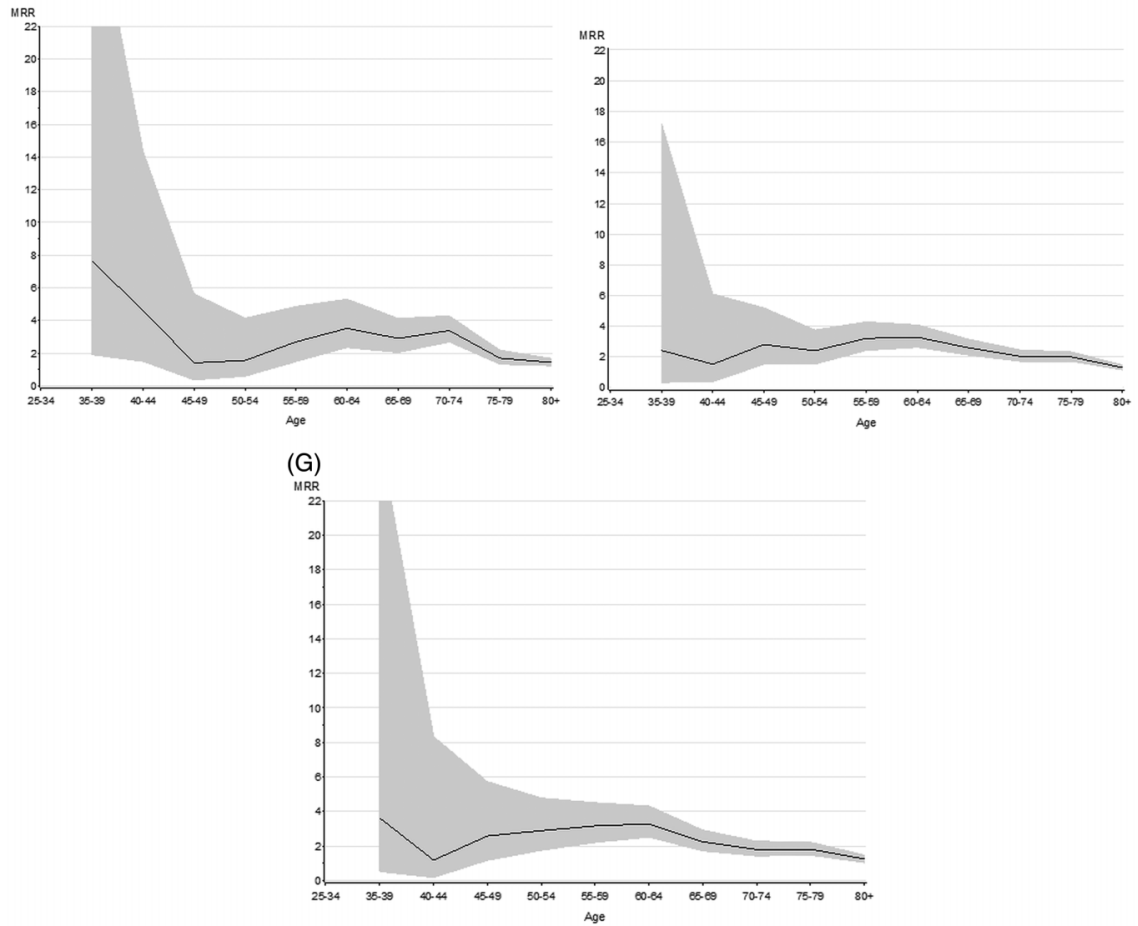

patients with bipolar disorder run almost twice the risk of dying from CVD than do persons in the general population, the mechanisms for which are currently unknown. ${ }^{45}$ There is a growing body of evidence from studies in other countries, and findings similar to ours have been observed in a representative study of the US population. ${ }^{15}$ In our previous study, ${ }^{5}$ standardised mortality ratios (SMR) for CVD, but not for cerebrovascular mortality, was higher for women compared to men. This difference was not found in our present study. SMR and MRR are relative measurements, affected both by population trends and trends among the cases. Thus, the different findings could be related both to changing death rates in the population and to changes among persons with bipolar disorder, or a combination of those factors. CVD contains several different causes of mortality, which may have different trends over time. However, the specific causes of death related to the sex difference in coronary heart disease mortality previously found cannot be answered in our study.

Studies have shown a higher cardiovascular mortality in persons with bipolar disorder type I compared to bipolar disorder type II or major depressive disorder. ${ }^{16} 17$ 
Figure 3 Mortality per 1000 person-years in persons with bipolar disorder and the general population adjusting for sex and calendar year for (A) coronary heart disease, $(B)$ acute myocardial infarction, and (C) cerebrovascular disease. All mortality rates presented with the same scale for reasons of comparison.

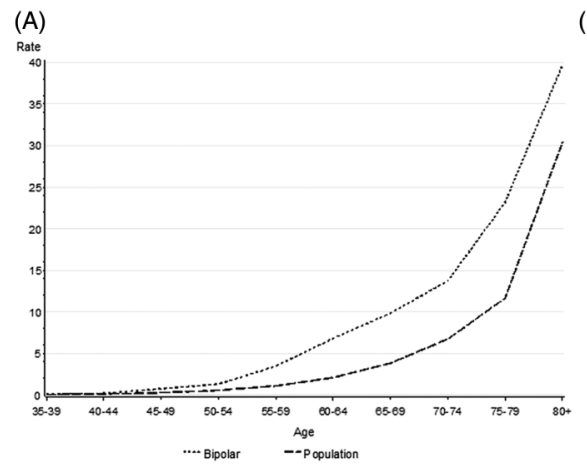

(B)

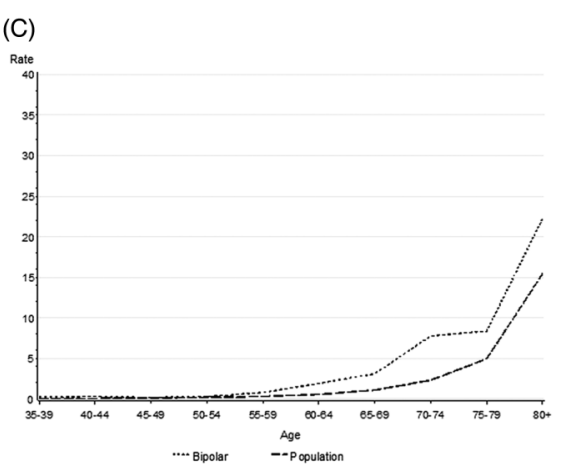

In our Swedish data, bipolar disorder type I cannot be separated from bipolar disorder type II. However, patients with bipolar disorder type I are much more likely to be hospitalised and thus to be included in our sample. Earlier age of CVD has been shown in several studies, ${ }^{15}$ and is also confirmed in our findings of increased cardiovascular death at a younger age compared to the population in Sweden. Possible risk factors for the increased mortality from CVD among patients with bipolar disorder may include adverse effects of medication, ${ }^{18} 19$ high levels of smoking, ${ }^{20}$ unhealthy diet, $^{21} 22$ lack of physical activity, ${ }^{21}$ low socialeconomic status $^{23}$ and lower rates of nutritional counseling. ${ }^{24}$ Studies have shown that patients with bipolar disorder deviate from the age-based norms on arterial stiffness measures. ${ }^{25}$ Also, inflammation has been pointed out as a potential biological cause of increased CVD in bipolar disorder $^{26} 27$ together with endothelial dysfunction. ${ }^{28}$ In addition, effects of genetic associations, such as those reported between type 2 diabetes, CHD and schizophrenia, ${ }^{29}$ could not be excluded. One of the most important loci of genetic polymorphisms linked to bipolar disease and depression is around the ATP-activated ion-channel receptor $P 2 X 7 . .^{30}$ Recently, a polymorphism in the $P 2 X 7$ gene was linked to the increased risk of stroke and acute myocardial infarction, ${ }^{31}$ and the same polymorphism has also recently been shown to be linked to cognitive symptoms in bipolar disorder, ${ }^{32}$ indicating that common genetic factors could have effect on both cardiovascular disease and bipolar disorder.

\section{CVD undertreated in persons with bipolar disorder}

Studies of patients with bipolar disorder have shown that they have an increased risk of the metabolic syndrome, ${ }^{33}$ that is, increased blood glucose ${ }^{34}$ and cholesterol levels, ${ }^{35}$ higher blood pressure ${ }^{36}$ and prevalence of overweight and obesity, ${ }^{21}$ closely associated with CVD. To prevent and treat metabolic disorders in patients with severe mental illnesses such as bipolar disorder, new guidelines for clinicians in Sweden were drawn up in 2009, thus after the end of this study, by psychiatrists, diabetologists, endocrinologists, cardiologists and general practitioners in collaboration. ${ }^{37}$ The guidelines can be found on the website of the Swedish Psychiatric

Table 2 Admission rate ratios (ARR) for persons with bipolar disorder during 1990-2006

\begin{tabular}{|c|c|c|c|c|c|c|c|}
\hline \multirow[b]{2}{*}{ Hospital admissions } & \multicolumn{2}{|l|}{ Men } & \multicolumn{2}{|c|}{ Women } & \multicolumn{2}{|c|}{ Total (both sexes) } & \multirow{2}{*}{$\begin{array}{l}\text { Excess cases } \\
(95 \% \mathrm{Cl})\end{array}$} \\
\hline & Cases & ARR (95\% Cl) & Cases & ARR $(95 \%$ Cl) & Cases & $\operatorname{ARR}(95 \% \mathrm{CI})$ & \\
\hline Cardiovascular disease & 540 & 1.27 (1.16 to 1.38$)$ & 696 & $1.33(1.24$ to 1.43$)$ & 1236 & $1.30(1.23$ to 1.38$)$ & 287 (218 to 356$)$ \\
\hline Cerebrovascular disease & 179 & 1.32 (1.14 to 1.53$)$ & 271 & 1.43 (1.27 to 1.62$)$ & 450 & 1.39 (1.26 to 1.52$)$ & 125 (84 to 167$)$ \\
\hline Coronary heart disease & 212 & 1.02 (0.89 to 1.17$)$ & 207 & 1.06 (0.92 to 1.21$)$ & 419 & $1.04(0.94$ to 1.14$)$ & $15(-25$ to 55$)$ \\
\hline Acute myocardial infarction & 133 & $0.96(0.81$ to 1.14$)$ & 137 & $1.11(0.94$ to 1.31$)$ & 270 & $1.03(0.92$ to 1.16$)$ & $8(-24$ to 41$)$ \\
\hline
\end{tabular}




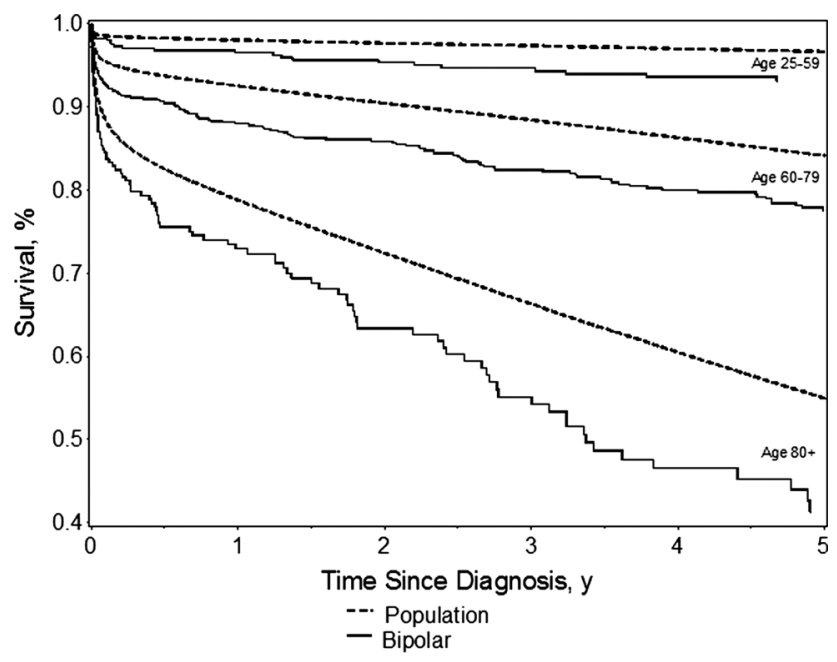

Figure 4 Five-year survival of cardiovascular disease in persons with bipolar disorder after discharge from first cardiovascular admission stratified by age at hospital contact.

Association (http://www.svenskpsykiatri.se). In the guidelines, there is a strong emphasis on the increased metabolic risks at younger age with focus both on primary and secondary prevention strategies and the need for collaboration between the different medical specialties. The effects of those guidelines are still to be evaluated.

Our finding that patients with bipolar disorder showed only slightly increased hospital admissions rates for CVD, despite their twice as high cardiovascular mortality, strongly suggests that CVD is undertreated in bipolar patients when compared to the general population. In a Danish study, the rates of invasive heart disease procedures were $40 \%$ lower among persons with bipolar disorder than in the general population. ${ }^{4}$ Although the younger age at cardiac events in bipolar disorder compared to the population may reduce detection, this factor is unlikely to cause the reduced rates of invasive heart procedures, since younger age at detection would rather be expected to lead to more intensive treatment. The lower rate of invasive heart disease procedures among persons with bipolar disorder is yet to be explained. Sudden cardiac mortality from cardiac arrest/ventricular fibrillation was increased among patients with bipolar disorder (MRR 1.85), but the 25 excess cases do not explain the difference in CVD admissions in terms of increased sudden death before hospital admission. Thus, the reasons for CVD undertreatment in bipolar disorder are not explained by the current findings. In our study, the MRR and ARR patient populations are slightly different, in the respect that the ARR patients are identified at their first index admission, while the MRR patients may have several admissions, and thus being more severely affected. Unequal access to healthcare (ie, receiving cardiac treatment of lower quality) for reasons other than financial has been previously suggested as a contributor to excess
CVD mortality in patients with severe mental disorders, such as schizophrenia, ${ }^{38}$ and may be indicated by our findings of increased mortality after the discharge from hospital compared to the population. These factors have not been studied extensively in bipolar patients. Healthcare in Sweden is free and is financed primarily through taxes. Therefore, it is unlikely that patients with bipolar disorder do not seek hospital care for lack of financial means.

Many mechanisms can contribute to the undertreatment of CVD among people with bipolar disorder. Our results indicate a failure of the healthcare system to identify and address the health needs of those patients, which has also been shown in other studies of people with severe mental disorders. ${ }^{39}$ The levels of CVD mortality in our persons with bipolar disorder are similar to those in schizophrenia, where adverse effects of antipsychotic medication have been considered the main contributing factor. When compared with a study of schizophrenia, a recent study of bipolar disorder in Stockholm County found that only $29 \%$ of patients with bipolar disorder were medicated with antipsychotics, ${ }^{40}$ as compared to practically all patients with schizophrenia, which raises the question of the importance of adverse effects of antipsychotics in CVD.

\section{CONCLUSIONS}

The observed number of deaths from cardiovascular diseases in patients with bipolar disorders was almost twice as high as the expected number in the general population, suggesting that more resources are needed for the prevention of these diseases in this patient group. Targeted interventions by effective collaboration between primary healthcare and psychiatric professionals would be crucial in the efforts to reduce excess CVD mortality in patients with bipolar disorder. Finally, effective cardiac treatment would ensure longevity and improved quality of life for patients with bipolar disorder.

\section{Author affiliations}

${ }^{1}$ Department of Neurobiology, Care Sciences, and Society, Centre for Family Medicine (CeFAM), Karolinska Institutet, Stockholm, Sweden

${ }^{2}$ Department of Medical Epidemiology and Biostatistics (MEB), Karolinska Institutet, Stockholm, Sweden

${ }^{3}$ Department of Mental Health and Substance Abuse Services, THL, National Institute for Health and Welfare, Helsinki, Finland

${ }^{4}$ Department of Cardiology, Lunds Universitet, Lund, Sweden

${ }^{5}$ Institute of Environmental Medicine, Karolinska Institutet, Stockholm,

Sweden

${ }^{6}$ Department of Molecular Medicine and Surgery, Neurogenetics, Karolinska Institutet, Stockholm, Sweden

${ }^{7}$ Center for Molecular Medicine, Karolinska Institutet, Stockholm, Sweden ${ }^{8}$ Department of Psychiatry, Tiohundra AB, Norrtälje, Sweden

Contributors UÖ had the idea of the study and is guarantor of the study together with $\mathrm{JH}$, who has performed the statistical analyses. JW has contributed to the design of the study and drafted the manuscript together with UÖ. KW, DE and LA have contributed to the design of the study and with revisions of the manuscript. All authors have approved the final version of the study. 
Funding This paper was supported by Swedish Council for Working Life and Social Research (grant number FAS 2008-0885) and Stockholm County Council (Grant number PPG-20120263). The study was conducted and analysed independently from its funders.

Competing interests All authors have completed the ICMJE uniform disclosure form (available on request from the corresponding author). JW, KW, LA, DE and UÖ has declared no support from any organisation for the submitted work, no financial relationship with any organisations that would have interest in the submitted work in the previous 3 years, and no other activities that could appear to have influenced the submitted work. UÖ has declared travelling expenses from Janssen-Cilag for attending a course in October 2012 unrelated to the study.

Ethics approval This study was approved by the ethical review board in Stockholm County. The ethical review board determined that informed consent from participating individuals was not required.

Provenance and peer review Not commissioned; externally peer reviewed.

Data sharing statement The analysis data set for this study is available from the National Board of Health and Welfare (Socialstyrelsen) in Sweden. Please contact $\mathrm{JH}$ for further information.

\section{REFERENCES}

1. World Health Organisation. Global atlas on cardiovascular disease prevention and control. Policies, strategies and interventions. WHO, 2011.

2. Socialstyrelsen. Folkhälsorapport. The national public health report 2009. Stockholm: The National Board of Health and Welfare in Sweden, 2009.

3. Laursen TM. Life expectancy among persons with schizophrenia or bipolar affective disorder. Schizophr Res 2011;131:101-4.

4. Laursen TM, Nordentoft M. Heart disease treatment and mortality in schizophrenia and bipolar disorder-changes in the Danish population between 1994 and 2006. J Psychiatr Res 2011;45:29-35.

5. Osby U, Brandt L, Correia N, et al. Excess mortality in bipolar and unipolar disorder in Sweden. Arch Gen Psychiatry 2001;58:844-50.

6. Laursen TM, Munk-Olsen T, Nordentoft M, et al. Increased mortality among patients admitted with major psychiatric disorders: a register-based study comparing mortality in unipolar depressive disorder, bipolar affective disorder, schizoaffective disorder, and schizophrenia. J Clin Psychiatry 2007;68:899-907.

7. Ludvigsson JF, Andersson E, Ekbom A, et al. External review and validation of the Swedish national inpatient register. BMC Public Health 2011;11:450.

8. Sellgren C, Landen M, Lichtenstein P, et al. Validity of bipolar disorder hospital discharge diagnoses: file review and multiple register linkage in Sweden. Acta Psychiatr Scand 2011;124:447-53.

9. Osby U, Tiainen A, Backlund L, et al. Psychiatric admissions and hospitalization costs in bipolar disorder in Sweden. J Affect Disord 2009;115:315-22.

10. Mclntyre RS, Danilewitz M, Liauw SS, et al. Bipolar disorder and metabolic syndrome: an international perspective. J Affect Disord 2010;126:366-87.

11. Zilber N, Schufman N, Lerner Y. Mortality among psychiatric patientsthe groups at risk. Acta Psychiatr Scand 1989;79:248-56.

12. Lawrence DM, Holman CD, Jablensky AV, et al. Death rate from ischaemic heart disease in Western Australian psychiatric patients 1980-1998. Br J Psychiatry 2003;182:31-6.

13. Kisely S, Smith M, Lawrence D, et al. Mortality in individuals who have had psychiatric treatment: population-based study in Nova Scotia. Br J Psychiatry 2005;187:552-8.

14. Roshanaei-Moghaddam B, Katon W. Premature mortality from general medical illnesses among persons with bipolar disorder: a review. Psychiatr Serv 2009;60:147-56.

15. Goldstein BI, Fagiolini A, Houck P, et al. Cardiovascular disease and hypertension among adults with bipolar I disorder in the United States. Bipolar Disord 2009;11:657-62.

16. Angst J, Hengartner MP, Gamma A, et al. Mortality of 403 patients with mood disorders 48 to 52 years after their psychiatric hospitalisation. Eur Arch Psychiatry Clin Neurosci 2012 (Epub ahead of print) doi:10.1007/s00406-012-0380-1
17. Fiedorowicz JG, Solomon DA, Endicott J, et al. Manic/hypomanic symptom burden and cardiovascular mortality in bipolar disorder. Psychosom Med 2009;71:598-606.

18. Sachs G, Bowden C, Calabrese JR, et al. Effects of lamotrigine and lithium on body weight during maintenance treatment of bipolar I disorder. Bipolar Disord 2006;8:175-81.

19. Newcomer JW. Medical risk in patients with bipolar disorder and schizophrenia. J Clin Psychiatry 2006;67:e16.

20. Lasser K, Boyd JW, Woolhandler S, et al. Smoking and mental illness: a population-based prevalence study. JAMA 2000;284:2606-10.

21. McElroy SL, Frye MA, Suppes T, et al. Correlates of overweight and obesity in 644 patients with bipolar disorder. J Clin Psychiatry 2002;63:207-13.

22. Kruger S, Shugar G, Cooke RG. Comorbidity of binge eating disorder and the partial binge eating syndrome with bipolar disorder. Int J Eat Disord 1996;19:45-52.

23. Druss BG, Zhao L, Von Esenwein S, et al. Understanding excess mortality in persons with mental illness: 17-year follow up of a nationally representative US survey. Med Care 2011;49:599-604.

24. Goodrich DE, Lai Z, Lasky E, et al. Access to weight loss counseling services among patients with bipolar disorder. J Affect Disord 2010;126:75-9.

25. Sodhi SK, Linder J, Chenard CA, et al. Evidence for accelerated vascular aging in bipolar disorder. J Psychosom Res 2012;73:175-9.

26. Goldstein BI, Kemp DE, Soczynska JK, et al. Inflammation and the phenomenology, pathophysiology, comorbidity, and treatment of bipolar disorder: a systematic review of the literature. J Clin Psychiatry 2009;70:1078-90.

27. Leboyer M, Soreca I, Scott J, et al. Can bipolar disorder be viewed as a multi-system inflammatory disease? J Affect Disord 2012;141:1-10

28. Rybakowski JK, Wykretowicz A, Heymann-Szlachcinska A, et al. Impairment of endothelial function in unipolar and bipolar depression. Biol Psychiatry 2006;60:889-91.

29. Ryan $\mathrm{MC}$, Collins $\mathrm{P}$, Thakore $\mathrm{JH}$. Impaired fasting glucose tolerance in first-episode, drug-naive patients with schizophrenia. $A m \mathrm{~J}$ Psychiatry 2003;160:284-9.

30. Lucae S, Salyakina D, Barden N, et al. P2RX7, a gene coding for a purinergic ligand-gated ion channel, is associated with major depressive disorder. Hum Mol Genet 2006;15:2438-45.

31. Gidlof $O$, Smith JG, Melander $O$, et al. A common missense variant in the ATP receptor $P 2 X 7$ is associated with reduced risk of cardiovascular events. PLoS ONE 2013;7:e37491.

32. Backlund L, Nikamo P, Hukic DS, et al. Cognitive manic symptoms associated with the P2RX7 gene in bipolar disorder. Bipolar Disord 2011;13:500-8.

33. Fiedorowicz JG, Palagummi NM, Forman-Hoffman VL, et al. Elevated prevalence of obesity, metabolic syndrome, and cardiovascular risk factors in bipolar disorder. Ann Clin Psychiatry 2008;20:131-7.

34. Birkenaes AB, Opjordsmoen S, Brunborg C, et al. The level of cardiovascular risk factors in bipolar disorder equals that of schizophrenia: a comparative study. J Clin Psychiatry 2007;68:917-23.

35. Fagiolini A, Frank E, Scott JA, et al. Metabolic syndrome in bipolar disorder: findings from the Bipolar Disorder Center for Pennsylvanians. Bipolar Disord 2005;7:424-30.

36. Johannessen L, Strudsholm U, Foldager L, et al. Increased risk of hypertension in patients with bipolar disorder and patients with anxiety compared to background population and patients with schizophrenia. J Affect Disord 2006;95:13-17.

37. Gothefors D, Adolfsson R, Attvall S, et al. Swedish clinical guidelines-prevention and management of metabolic risk in patients with severe psychiatric disorders. Nord J Psychiatry 2010;64:294-302.

38. Laursen TM, Munk-Olsen T, Agerbo E, et al. Somatic hospital contacts, invasive cardiac procedures, and mortality from heart disease in patients with severe mental disorder. Arch Gen Psychiatry 2009;66:713-20.

39. Manderbacka K, Arffman M, Sund R, et al. How does a history of psychiatric hospital care influence access to coronary care: a cohort study. BMJ Open 2012;2:e000831.

40. Adler M, Backlund L, Edman G, et al. Symptoms and treatment of bipolar patients in Sweden. Int J Psychiatry Clin Pract 2012; $16: 170-7$ 